\title{
PENANAMAN MANGROVE DI DALAM POT
}

\section{Mangrove Planting in Pot}

\author{
Sarno \\ Jurusan Biologi Fakultas Matematika dan Ilmu Pengetahuan Alam Universitas Sriwijaya, \\ Kampus Unsri Indralaya, Ogan Ilir, Sumatera Selatan 30662 \\ Program Studi Ilmu Pertanian, Pascasarjana Universitas Sriwijaya \\ Jl. Padang Selasa 524, Bukit Besar, Palembang Sumatera Selatan 30139 \\ E-mail: sarno_klaten65@yahoo.co.id
}

\begin{abstract}
Mangroves of several species very attractive when planted in pots. This paper is based on experimental results and the introduction of mangrove as ornamental plants to the public. Is expected to provide information and inspiration on the selection and species of mangrove prospects as an ornamental plant in the pot. Selection of mangrove species depends on the tastes. So far, not many are trying intensively for business purposes, so that a prospective opportunities. Utilization of mangrove should be carried out with due regard to preservation.
\end{abstract}

Keywords: mangrove potted, propagule, unique, attractive

\begin{abstract}
Abstrak - Jenis mangrove tertentu sangat menarik jika ditanam di dalam pot. Tulisan ini dibuat berdasarkan hasil percobaan dan pengenalan mangrove sebagai tanaman hias kepada masyarakat. Diharapkan dapat memberikan informasi dan inspirasi tentang pemilihan jenis dan prospek mangrove sebagai tanaman hias dalam pot. Pemilihan jenis mangrove tergantung kepada selera masing.masing. Selama ini belum banyak yang mencoba secara intensif untuk kepentingan bisnis, sehingga menjadi peluang yang prospektif. Pemanfaatan mangrove seyogyanya dilakukan dengan tetap memperhatikan pelestariannya.
\end{abstract}

Kata kunci: mangrove dalam pot, propagul, unik, atraktif

\section{PENDAHULUAN}

Istilah mangrove sudah sering digunakan dalam berbagai penulisan karya tulis ilmiah. Akan tetapi istilah tersebut belum dibakukan, artinya belum tertulis di dalam Kamus Besar Bahasa Indonesia (KBBI), yang sudah ada di dalam KBBI adalah istilah bakau. Kedua istilah tersebut sebenarnya merujuk kepada hal yang sama. Pengertian daribakau atau mangrove(Sarno, 2015) adalah komunitas rawa pantai berair payau yang didominasi oleh pohon-pohon Rhizophora, Sonneratia, Bruguiera, yang sering berakar nafas; (KBBI, 2005) jenis tumbuhan dari marga Rhizophora yang hidup di daerah pantai tropik, perawakannya berbentuk pohon kecil, mempunyai akar tiang banyak dan bijinya sudah berkecambah sebelum buahnya gugur; tumbuhan pokok di pantai, termasuk marga Rhizophora kulit batangnya biasa dipakai untuk menyamak kulit, macamnya banyak sekali. Contoh: bakau akik, bakau hitam, bakau minyak, bakau merah, dan bakau jangkar.

Penulis menggunakan istilah mangrove, semata-mata karena sudah familier dan sering digunakan dalam berbagai tulisan ilmiah. Manfaat dari 
mangrove sudah dipahami baik secara ekologi, biologi dan ekonomi. Contoh yang menarik adalah beberapa jenis dari Rhizophoraceae yaitu Rhizophora mucronata, $R$. apiculata dan Bruguiera gymnorrhiza dengan propagul sebagai sarana perkembangbiakan. Perakarannya yang dapat memecah ombak air laut pasang.

Ekosistem mangrove menyajikan keindahan alam yang unik, asri dan eksotik. Pemanfaatan ekosistem sebagai tujuan wisata di Indonesia sudah dapat dikunjungi pada berbagai tempat, seperti di Bali, Malang, Surabaya, Pantai Indah Kapuk, Cilacap, Riau dan masih ada beberapa tempat yang lain. Wisata mangrove tersebut secara apa adanya atau in situ memperlihatkan keindahan ekosistem mangrove.

Mangrove yang ditanam di dalam pot memberikan kesan antik, unik, dan atraktif. Antik karena tidak seperti biasanya, jarang diberdayakan tetapi masih memberikan nilai sebagai hasil karya seni. Unik artinya lain daripada yang lain. Sebagaimana vegetasi mangrove merupakan sekelompok tanaman yang unik dalam arti hidup diantara daratan dan lautan (Tomlinson, 1986, Vannucci, 2001). Tampilan tanaman hias dari mangrove memberi kesan atraktif, mempunyai data tarik atau bersifat menyenangkan/menarik (Quillen, 2007).

Manfaat mangrove yang belum banyak diketahui oleh masyarakat adalah potensinya sebagai tanaman hias jika ditanam di dalam pot. Permasalahannya adalah Jenis apa yang digunakan atau dipilih; bagaimana membuat mangrove sebagai tanaman hias/mangrove dalam pot; dan bagaimana prospeknya? Melalui tulisan ini penulis bertujuan untuk memberikan informasi tentang potensi mangrove sebagai tanaman hias; jenis mangrove yang memiliki prospek sebagai tanaman hias. Bibit Rhizophora stylosa (Baba et al., 2013) dijual sebagai cendera-mata kepada wisatawan di Iriomote dan Ishigaki, Jepang.

\section{METODE PENELITIAN}

Tulisan ini merupakan kajian yang diperoleh berdasarkan pengalaman penulis dalam kegiatan Tri Dharma Perguruan Tinggi dan studi literatur. Pengalaman mengajar Mata Kuliah Pilihan Konservasi Mangrove, riset atau survey pada ekosistem mangrove dan kegiatan Pengabdian kepada Masyarakat. Pustaka yang terkait dengan manfaat mangrove sebagai tanaman hias masih terbatas. Hal ini dikarenakan belum banyak dilakukan oleh masyarakat.

Berdasarkan percobaan terhadap pembibitan mangrove dan pengenalan pemanfaatan mangrove sebagai tanaman hias disajikan tulisan ini. Studi pustaka yang terkait dengan permasalahan, pustaka primer dan terkini dilakukan untuk menambah kajian agar lebih komprehensip.

\section{HASIL DAN PEMBAHASAN}

\section{Biologi Mangrove}

Mangrove bukanlah suatu

kelompok genetik tunggal tetapi mewakili sejumlah besar variasi/ veritas dari famili tumbuhan yang telah beradaptasi terhadap lingkungan pasang surut daerah tropik. Tomlinson (1986) mengelompokkan mangrove menjadi tiga kelompok, yaitu: jenis mangrove major; jenis mangrove minor; dan asosiasi mangrove. Jenis mangrove minor merupakan bagian jenis yang kurang mencolok dari suatu vegetasi dan jarang membentuk tegakan murni. Jenis major merupakan mangrove sejati atau mangrove utama/sempurna.

Mangrove sejati memiliki semua atau sebagian besar kriteria sbb.: berada secara ekslusif di ekosistem mangrove; 
memegang peranan penting dalam struktur komunitas dan mempunyai kemampuan membentuk tegakan murni; mempunyai spesialisasi secara morfologis-seperti akar nafas dan mekanisme pertukaran gas; memiliki mekanisme secara fisiologis untuk pengeluaran garam (salt exclusion) dan atau eksresi garam memiliki sistem reproduksi viviparous; secara taksonomi terisolasi dari tanaman daratan pada tingkat genetik dan seringkali pada sub-famili atau tingat famili. Menurut Tomlinson (1986), mangrove major meliputi 34 jenis dalam 9 genera dan 5 famili. Mangrove minor mencakup 20 jenis dalam 11 genera dan 11 famili. Sehingga total sekarang secara global ada 54 jenis mangrove dalam 20 genera dan 16 famili.

\section{Fungsi dan Manfaat Mangrove}

Mangrove merupakan ekosistem yang sangat produktif dan memiliki fungsi ganda yaitu fungsi sosialekonomi dan fungsi ekologi. Berbagai produk dari mangrove dapat dihasilkan secara langsung maupun tidak langsung, diantaranya: kayu bakar, bahan bangunan, keperluan rumah tangga, kertas, kulit, obat-obatan, dan perikanan Mangrove juga mempunyai peranan penting dalam melindungi pantai dari gelombang, angin, dan badai. Tegakan mangrove dapat melindungi pemukiman, bangunan, dan pertanian dari gelombang pasang (Noor et al., 2006).

Fungsi mangrove mencakup fungsi fisik, fungsi biolpogi dan fungsi ekonomi. Fungsi fisik: secara fisik mangrove berfungsi sebagai pelindung pantai dan tebing sungai dari erosi/ abrasi, mempercepat sedimentasi, mengendalikan intrusi air laut, dan melindungi daerah belakang mangrove dari gelombang tinggi dan angin kencang. Fungsi biologi: dilihat dari aspek bologi, mangrove merupakan tempat yang ideal bagi ikan, udang, kepiting dan biota laut lainnya untuk mencari makan, memijah dan berkembangbiak dan hutan mangrove juga sebagai tempat bersarangnya burung-burung laut. Fungsi ekonomi: fungsi ekonomi dari hutan mangrove dapat dilihat dari segi pemanfaatan kayu dan non kayu. Kayu mangrove dapat juga dimanfaatkan sebagai bahan bangunan dan penghasil pulp dan arang dengan kualitas tinggi (Tomlinson, 1986).

Pemanfaatan fauna mangrove: beberapa jenis ikan, udang dan kepiting banyak dibudidayakan di tambak, diantaranya ikan bandeng (Canos canos), belanak (Mugil cephalus), kepiting bakau (Escyla cerrata) dan tiram bakau (Crustacea cuculata). Pemanfaatan hasil hutan mangrove: bahan baku bangunan, konstruksi, perahu; kayu bakar dan arang (Rhizophora, Bruguiera).; bahan baku kertas.beberapa jenis mangrove dapat dimanfatkan sebagai obat-obatan, gula makanan dan bahan racun ikan yang ramah lingkungan. kulit batang Ceriops tagal baik sekali untuk mewarnai dan pengawet jala ikan. Bruguiera sp., juga menjadi tempat yang ideal untuk sarang lebah (lebah madu). kawasan mangrove juga sangat cocok sebagai tempat budidaya rumput laut. Pemanfaatan lain: Kondisi vegetasi mangrove yang mangrove yang khas dan unik akan sangat mungkin dikembangkan sebagai obyek wisata, ekowisata, tempat 
penelitian dan pendidikan lingkungan bagi siswa sekolah. Mangrove sebagai tanaman hias belum banyak dibahas.

\section{Memilih Jenis Mangrove untuk Tanaman Hias}

Menurut Curran et al. (2006), beberapa jenis mangrove dapat dengan mudah ditanam dan tumbuh di dalam media hydroponic atau di dalam pot tanaman. Contoh jenis mangrovenya adalah: Aegiceras corniculatum, Bruguiera exaristata, B. gymnorrhiza dan Rhizophora stylosa. Jenis mangrove yang digunakan sebenarnya tergantung dari selera masing-masing. Beberapa yang pernah dicoba adalah jenis dari Rhizophoraceae. Mangrove memberikan gambaran tanaman yang secara habitus: unik dan eksotis-terutama penampilan propagul dan tipe akarnya, seperti perakaran Rhizophoraapiculata(Gambar1).Perakaran tersebut memberikan gambaran kondisi alami untuk tumbuhan yang sudah tua. Jika diberdayakan sebagai tanaman hias di dalam pot sangat unik dan menarik sehingga prospektif.

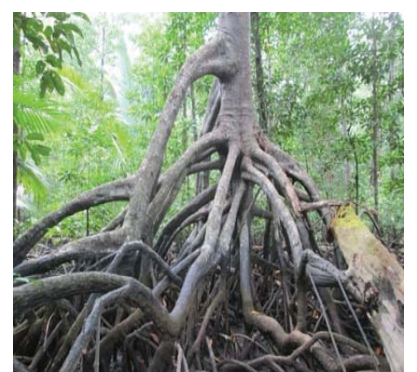

Gambar 1. Akar tunjang R. apiculata di hutan primer Taman Nasional Sembilang, Sumatera Selatan (Sumber: Sarno et al., 2014)

Penanaman di dalam pot dapat secara langsung dari propagul atau melalui pembibitan di dalam polibeg terlebih dahulu. Jika menginginkan variasi yang lain, misalnya menanam dengan melakukan pemotongan propagul juga menarik. Propagul yang dipotong masih dapat tumbuh. Akar dapat keluar dari bekas potongan propagul (Gambar 2).
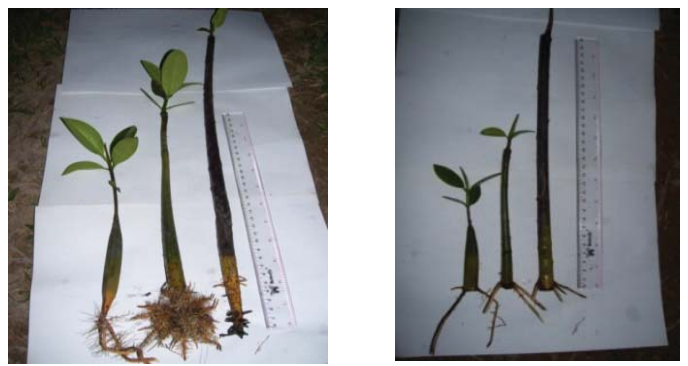

Gambar 2. Bibit berumur 10 minggu (dari kiri ke kanan berturut-turut adalah B. gymnorrhi$z a, R$. apiculata dan R. mucronata); (atas) tanpa pemotongan; (bawah) dengan pemotongan propagul) (Sumber: Sarno, 2009)

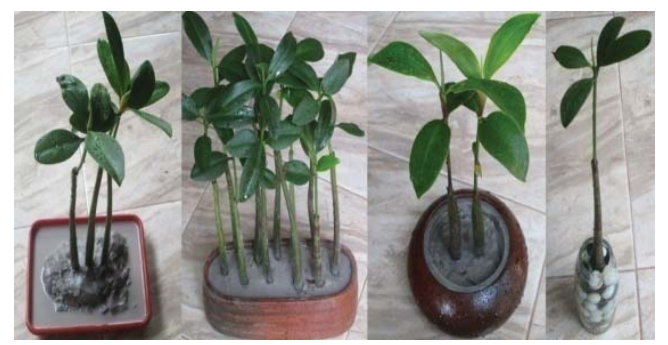

Gambar 3. Contoh mangrove yang ditanam dalam media air tawar (Sumber: Sarno et al., 2014)

Gambar 3, merupakan contoh mangrove yang ditanam dengan media tanah terrestrial dan air tawar. Semuanya merupakan bibit yang berumur 3 bulan setelah tanam. Gambar pertama dan dan kedua adalah jenis $R$. apiculata dan gambar ketiga adalah B. gymnorrhiza. Gambar keempat adalah $R$. apiculata yang tumbuh hanya dengan air tawar saja tanpa adanya tanah, kelereng yang digunakan dimaksudkan agar tanaman dapat berdiri tegak.

Mangrove yang ditanam dengan air tawar masih dapat tumbuh akan 
tetapi pertumbuhannya lambat tidak seperti jika hidup di habitatnya (de Silva dan Amarasinghe, 2010). Mangrove tidak memerlukan garam untuk hidupnya (Tomlinson, 1986) tetapi mampu beradaptasi terhadap habitat dengan salinitas tertentu. Justru kondisi seperti itu yang dianggap menarik jika diharapkan sebagai tanaman hias, tetap hidup tetapi pertumbuhannya lambat.

Penanaman di dalam pot dapat secara langsung dari propagul atau melalui pembibitan di dalam polibeg terlebihdahulu.Jikamenginginkanvariasi yang lain, misalnya menanam dengan melakukan pemotongan propagul juga menarik. Propagul yang dipotong masih dapat tumbuh. Akar dapat keluar dari bekas potongan propagul (Gambar 2). Bekas potongan propagul dapat diberi perlakuan zat pengatur tumbuh untuk merangsang keluarnya akar (de Silva dan Amarasinghe, 2010).

\section{Prospek Tanaman Hias Mangrove}

Mangrove dapat ditanaman pada media dengan air tawar (Gambar 3) atau pun dengan air payau (Gambar 4 dan Gambar 5). Beberapa contoh mangrove yang sudah dicoba sebagai tanaman hias yang ditanam dalam media dengan air payau/salin dapat diunduh dari internet dengan alamat website https://www.google.com/h?q=mangrov e+in+aquarium\&client=firefox- $\quad$ (Gambar 4).

Setelah diunggah ke dalam media massa (facebook) pada http://www. facebook.com/sar.no.77. 9 November 2013, banyak komentar yang antara lain adalah bahwa mangrove sebagai tanaman hias berpotensi secara finansial. maksudnya adalah dapat dijadikan sebagai wirausaha atau mempunyai peluang bisnis.
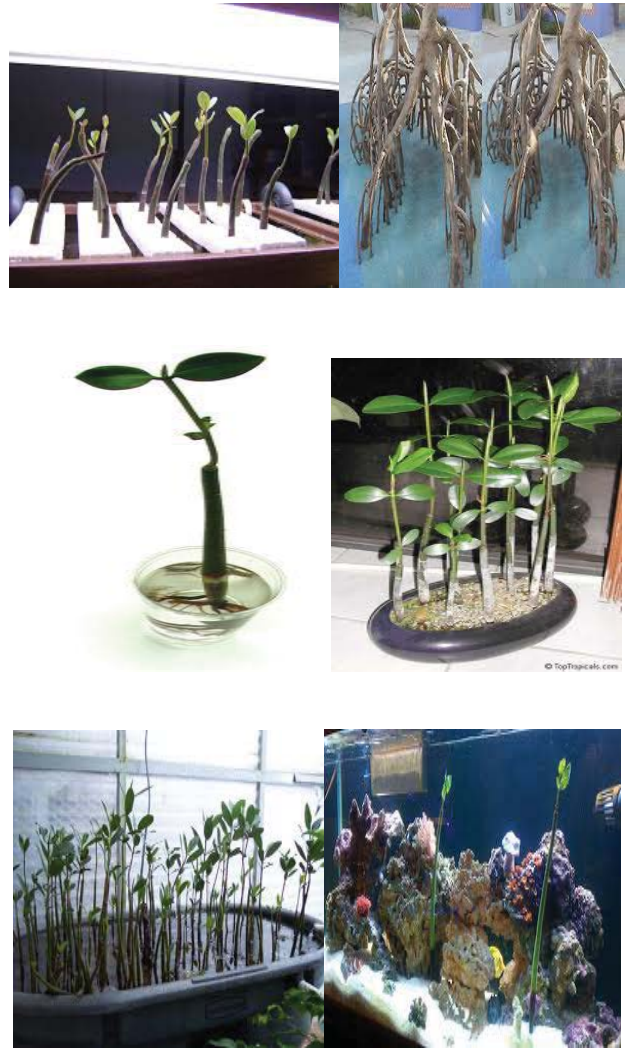

Gambar 4. Beberapa mangrove pada media air payau

(Sumber:https://www.google.com/ search?q=mangrove+in+aquarium\&client=firefox-)

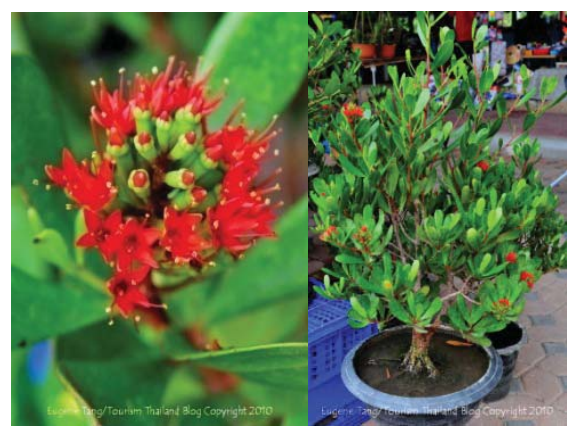

Gambar 5. Mangrove Lumnitzera littorea (Red Teruntum) sebagai tanaman hias di Thailand (Sumber: http://www.eugenegoesthailand. $\operatorname{com} / \mathrm{p}=9215$ )

\section{Pananaman Propagul dan Perawatannya}

Cara membuat tanaman hias dari mangrove cukup mudah, sederhana dan 
tidak memerlukan biaya yang tinggi. Bahan dapat dipilih dari bibit mangrove atau tanam langsung propagul (Gambar 6) ke media tumbuh atau pot. Media tumbuh dapat digunakan tanah, lumpur atau bahkan hanya air tawar saja dari sekitar tempat tinggal, tidak harus menggunakan media dimana mangrove tumbuh secala alami.

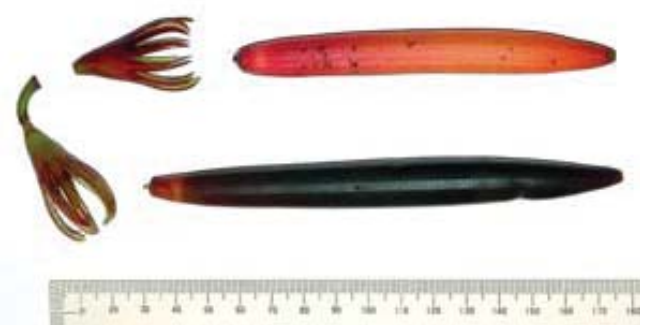

Gambar 6. Propagul Bruguiera gymnorrhiza (Allen and Duke, 2006)

Bahan yang diperlukan: propagul $R$. mucronata dan atau $R$. apiculata, tanah/lumpur sebagai media tanam, pot, dan polibeg. Alat yang digunakan: cangkul, cetok semen, sarung tangan, ember, spreyer tangan, dan kamera. Cara Kerja adalah sebagai berikut: Disiapkan bahan dan alat yang akan dipergunakan; Propagul yang sudah siap dapat langsung ditanam, disusun dalam pot yang sudah diisi media tanah atau lumpur; ropagul dapat juga ditanam dahulu di polibeg yang sudah berisi media tanah/lumpur. Jika sudah menjadi bibit, kemudian setelah muncul sepasang daun mengembang penuh baru dipindahkan ke dalam pot/vas bunga; Pemilihan pot/vas sesuai dengan selera atau keinginan pembuat tanaman hias. Pot/vas yang dipakai adalah yang tidak berlubang bagian bawahnya, sehingga air yang diberikan tidak keluar dari pot. Pot/wadah dapat diganti dengan yang lebih bagus/menarik jika tanaman sudah dianggap adaptif dengan medianya; Air yang digunakan dapat air tawar atau air payau. Bibit mangrove dapat tumbuh pada air tawar tanpa ditambah media tanah/lumpur.

Diusahakan media tanah/ lumpur jangan sampai kering. Bahkan dalam kondisi selalu basah atau sedikit tergenang tidak masalah bagi pertumbuhan bibit mangrove. Tanaman hias masih mampu bertahan beberapa tahun jika cukup air dan aman dari hama. Jangan terlalu lama ditempatkan di ruangan/tempat gelap. Diusahakan mendapat cahaya matahari yang cukup. Jika diperlukan, dapat diberikan pupuk. Jika terserang hama segera dikendalikan dengan insektisida, karena biasanya dari jenis serangga yang mengganggu bibit mangrove ini.

\section{Kendala dan Solusinya}

Bagian yang menarik dari mangrove sebagai tanaman hias adalah tipe akar, terutama akar tunjang. Tipe akar ini dimiliki oleh jenis $R$. apiculata dan $R$. mucronata. Bentuk akarnya sangat khas, unik dan eksotis. Jenis mangrove tersebut sangat menarik jika dapat dijadikan sebagai tanaman hias. Kedua jenis mangrove tersebut dapat dengan mudah dibibitkan secara ex situ. Media tanah bukan dari habitatnya dan dengan air tawar pun dapat tumbuh dengan baik. Pembibitan B. gymnorrhiza, $R$. apiculata dan $R$. mucronata dengan air tawar yang siap tanam pada umur 4 bulan dengan kriteria jumlah daun masing-masing 5, 4 dan 3 pasang, sedangkan tinggi tunas masing-masing $27,5 \mathrm{~cm}$; $31,0 \mathrm{~cm}$; dan 32,5 cm (Sarno, 2009; Sarno dan Ridho, 2009). Sehingga dengan demikian jika ditanam sebagai tanaman hias akan 
mudah membuat dan merawatnya. Kendala yang dirasakan adalah cara mendapatkan buah/propagul jenis mangrove tersebut.

Umumnya mangrove tumbuh di kawasan pesisir atau pantai daerah tropis dan subtropik (Tomlinson, 1986). Lokasinya jauh dengan pemukiman dan tidak semua orang mempunyai kesempatan memasuki kawasan hutan mangrove. salah satu langkah yang dapat ditempuh adalah meminta bantuan atau kerjasama dengan nelayan atau masyarakat pesisir untuk mendapatkan propagul untuk ditanam di dalam pot sebagai tanaman hias.

\section{SIMPULAN, SARAN, DAN REKOMENDASI}

Jenis mangrove tertentu sangat menarik jika ditanam di dalam pot. Penyebarluasan informasi tentang mangrove sebagai tanaman hias dapat melalui percobaan dan publikasi kepada masyarakat luas. Selama ini belum banyak yang mencoba secara intensif untuk kepentingan bisnis, sehingga menjadi peluang yang prospektif.

Pemanfaatan mangrove seyogyanya dilakukan dengan tetap memperhatikan pelestariannya. Pemilihan jenis tergantung pada selera masing-masing.

Setelah dicoba ditanam di dalam pot, mangrove jenis tertentu juga dapat dicoba ditanam untuk menghiasi akuarium. Hal ini sudah dicoba oleh orang manca negara dan informasinya dengan mudah diunduh melalui internet. Kata kunci yang dapat digunakan adalah mangrove potted atau mangrove aquarium. Sepengetahuan penulis belum ada toko bunga atau tanaman hias yang menjual tanaman mangrove dalam pot.
Tanaman mangrove dalam pot dapat diperuntukan tidak hanya untuk keperluan sendiri, akan tetapi dapat dikembangkan pada skala yang lebih luas, misalnya untuk di kantor, instansi atau hotel. Keuntungannya adalah perawatan yang mudah dan tahan lama hidup dengan air dan cahaya matahari yang cukup.

\section{DAFTAR PUSTAKA}

Allen, J.A. and Duke, N.C. 2006. Bruguiera gymnorrhiza (large-leafed mangrove), ver. 2.1. In: Elevitch, C.R. (ed.). Species Profiles for Pacific Island Agroforestry. Permanent Agriculture Resources (PAR), Hōlualoa, Hawai'i. <http:// www.traditionaltree.org $>$.

Baba, S., Chan, H.T. \& Aksornkoae, S. 2013 Useful Products from Mangrove and other Coastal Plants. ISME Mangrove Educational Book Series No. 3. International Society for Mangrove Ecosystems (ISME), Okinawa, Japan, and International Tropical Timber Organization (ITTO), Yokohama, Japan.

Curran, M., Allaway, W.G. and Cole, M. 2006. Artificial Tidal System for Growing Mangroves. School of Biological Science. University of Sydney, NSW.

de Silva, K.H.W.L. and Amarasinghe, M.D. 2010. Vegetative Propagation of some Selective Mangrove Species from Negombo Estuary, Sri Lanka. Sri Lanka J. Aquat. Sci., 15(2010): 25-38.

KAMUS BESAR BAHASA INDONESIA/ Tim Penyusun Kamus Pusat Bahasa, Edisi Ketiga. 2005. Pusat Bahasa 
Departemen Pendidikan Nasional. Balai Pustaka, Jakarta.

Noor, R.Y., M. Khazali, dan I.N.N. Suryadiputra. 2006. Panduan Pengenalan Mangrove di Indonesia. PKA/WI-IP, Bogor.

Quillen, K. 2007. Artist Exhibits Sea Bean Jewelry: Exotic locales offer materials. Florida Today. Available at http:// www.floridatoday.com/apps/pbcs. $\mathrm{d} l 1 /$ article? $\mathrm{AID}=2007704270302$. Accessed 10 January 2016.

Sarno dan Ridho, M.R. 2009. Pembibitan Mangrove Secara Ex Situ dengan Air Tawar dalam Upaya Konservasi Biodiversitas Mangrove. Makalah disampaikan pada Kongres Nasional Perhimpunan Biologi Indonesia XIV dan Seminar Nasional Biologi XX Universitas Islam Negeri (UIN) Malang, 24 - 25 Juli 2009.

Sarno. 2009. Pengaruh Pemotongan Buah tehadap Viabilitas Bibit Mangrove. Makalah disampaikan pada Kongres Nasional Perhimpunan Biologi Indonesia XIV dan Seminar Nasional Biologi XX Universitas Islam Negeri (UIN) Malang, 24 - 25 Juli 2009.

Sarno. 2013. Mangrove sebagai Tanaman Hias dalam Media Air Rawar. https:// www.facebook.com/sar.no.77. 9 November 2013.

Sarno dan Melky. 2014. Konservasi Mangrove. Buku Ajar. Program Studi Ilmu
Kelautan. FMIPA Universitas Sriwijaya, Indralaya.

Sarno, Widjajanti, H., Ridho, M.R., Windusari, Y., dan Setiawan, A. 2014. Introduksi Pemanfaatan Tanaman Mangrove sebagai Tanaman Hias. Laporan PPM. Dibiayai dari BOPTN Universitas Sriwijaya No. SPDIPA-023.04.2.415112/2014 tanggal 5 Desember 2013 Sesuai dengan Surat Perjanjian Pelaksanaan kegiatan Pengabdian Masyarakat No. 250.23/FP/UN9.3.2/PM/2014, tanggal 5 Juni 2014.

Sarno. 2015. Kamus Mangrove. Penerbit Simetri. Palembang. viii +116 Halaman. ISBN: 978-602-1160-11-4.

Tomlinson, P.B. 1986. The Botany of Mangroves. Cambridge, New York, USA: Cambridge Tropical Biology Series, Cambridge University Press, xii+419.

Vannucci, M. 2001. What is so special about mangroves? Braz. J. Biol., 61(4): 599-603.

www.google.com/search? q=mangrove + in + aquarium \&client $=$ firefoxa\&hs=1Cl\&rls=org.a:id:official \&channel $=\mathrm{np} \& \mathrm{tbm}=\mathrm{isch} \& \mathrm{tbo}=$ u\&source $=$ univ\&sa $=X \& e i=4 w$ 5LUvvnMpDtrQex1IGACw\&sAQ\&biw=1024\&bih=437\&dpr=1). Diakses Tanggal 2 Oktober 2013. 